\title{
Hydrogeochemical transport modeling of the infiltration of tertiary treated wastewater in a dune area, Belgium
}

Hydrogeology Journal, electronic supplementary material: model calibration

\author{
Alexander Vandenbohede ${ }^{1}$, Ilka Wallis ${ }^{2}$, Emmanuel Van Houtte ${ }^{3}$, Eric Van Ranst ${ }^{1}$ \\ ${ }^{1}$ Dept. Geology and Soil Science, Ghent University, Krijgslaan 281 (S8), B-9000 Gent, \\ Belgium \\ alexander.vandenbohede@ugent.be \\ ${ }^{2}$ School of the Environment, Flinders University, Adelaide, GPO Box 2100, SA \\ 5001, Australia \\ ${ }^{3}$ Intermunicipal Water Company of the Veurne region (I.W.V.A.), Doornpannestraat 1, B- \\ 8670 Koksijde, Belgium
}

\section{Introduction}

The flow and conservative transport model is calibrated using head observations in observation wells, chloride concentrations in the extraction wells and the results of a tracer test. Figure ESM1 shows a general lay-out of the MAR system with location of the infiltration ponds, extraction wells and observation wells used for the calibration. Figure ESM2 shows the model domain and screen depths of the observations wells. WP24 and WP23 are at a distance of respectively 9 and $29 \mathrm{~m}$ from the eastern pond. Both wells contain three screens of $1 \mathrm{~m}$ length at a depth of $3 \mathrm{~m}$ (XX.4), $7 \mathrm{~m}$ (XX.3) and $11.5 \mathrm{~m}$ (XX.2).

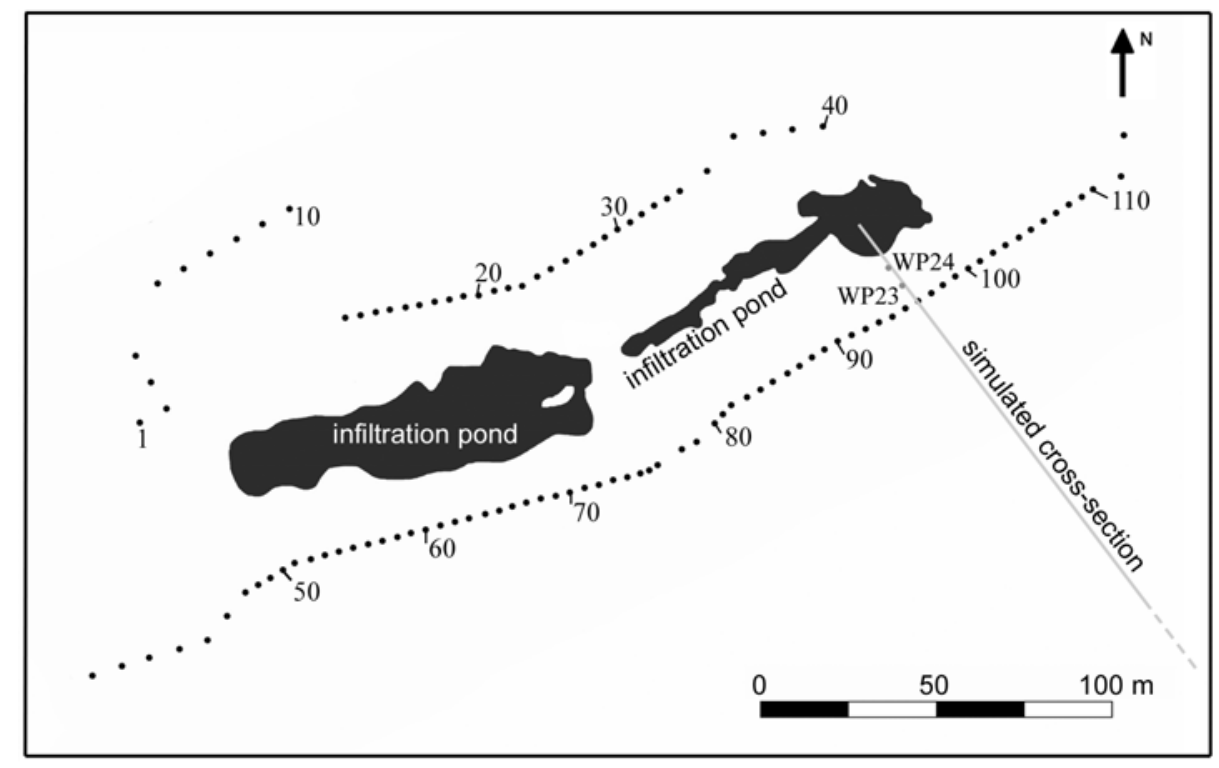

Figure ESM1 Lay-out of the infiltration ponds, wells of the well battery (dots) and the location of the observation wells (WP23 and WP24). Wells of the well battery are numbered with an interval of 10 


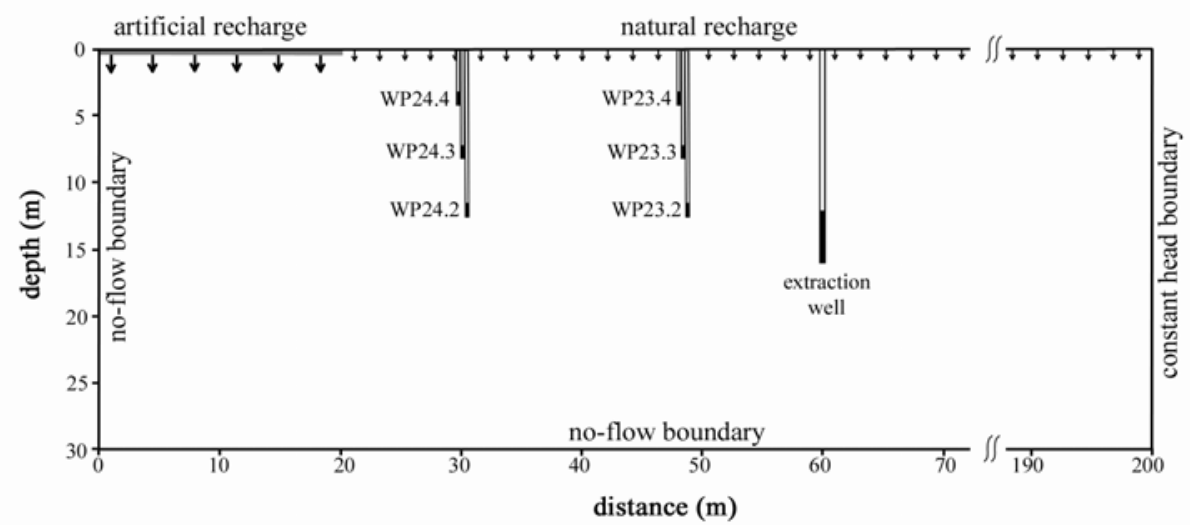

Figure ESM2 Conceptual model for the simulation with indication of the pond (first $20 \mathrm{~m}$ ), observation wells (WP24 and WP23) and the extraction well

\section{Flow model calibration}

Figure ESM3 shows the comparison between calculated and observed head observations in WP24 and WP23. An overall good fit is obtained with the exception of the first part of 2003 and late 2007-early 2008. During 2007, decreased infiltration due to clogging happened. Infiltration rate per surface area in both ponds was therefore not the same. The difference in infiltration rate in both ponds is not known since only the total infiltration rate is known. Infiltration rates in the simulation are not taking this into account which explains the difference between observations and simulations.

The same applies for 2003. The first part of 2003 shows an increase in both infiltration and extraction rate from more variable conditions (the start-up period) to long-term stable rates. Here, its seems also likely that more water has infiltrated in the eastern pond, which is not taken into account using equally distributed rates.
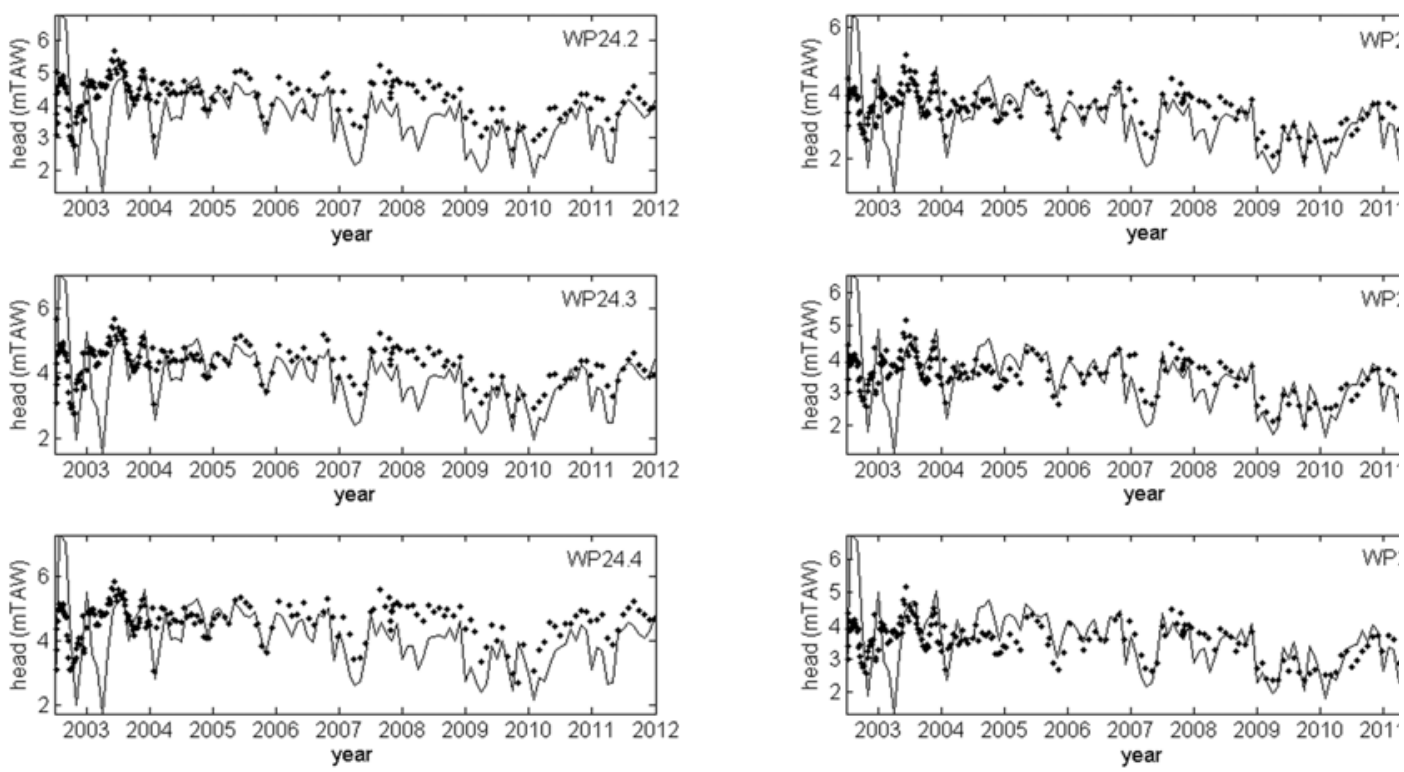

Figure ESM3 Comparison of calculated (grey line) and observed heads (dots) in observation wells WP24 and WP23 


\section{Conservative transport model calibration}

$\mathrm{Cl}^{-}$and $\mathrm{F}^{-}$are considered as conservative tracers (Vandenbohede et al., 2009). Therefore, $\mathrm{Cl}^{-}$ as function of time in the extraction well and a tracer test with NaF dissolved in the recharge water (Vandenbohede et al., 2008) are used for calibration of the conservative transport model.

Figure ESM4 gives a comparison between calculated $\mathrm{Cl}^{-}$concentrations in the extraction well and observed $\mathrm{Cl}^{-}$concentrations in extraction wells 94 to 97. These wells are located closed to the cross-section and yearly $\mathrm{Cl}^{-}$measurements are available. An overall good comparison is obtained. Of note is that the $\mathrm{Cl}^{-}$concentrations can differ considerably between different, even nearby, wells because of concentration differences in the native dune water. The mean $\mathrm{Cl}^{-}$value in the shallow part of the aquifer is $0.85 \mathrm{mmol} / \mathrm{L}$ with a variance of $0.35 \mathrm{mmol} / \mathrm{L}$. Chloride concentration tends to increase with depth and can locally be as high as 3.25 $\mathrm{mmol} / \mathrm{L}$ in some parts of the dune aquifer. A mean $\mathrm{Cl}^{-}$concentration in the aquifer of 1.7 $\mathrm{mmol} / \mathrm{L}$ is used for the simulation, which is a mean value at the location of the cross-section.

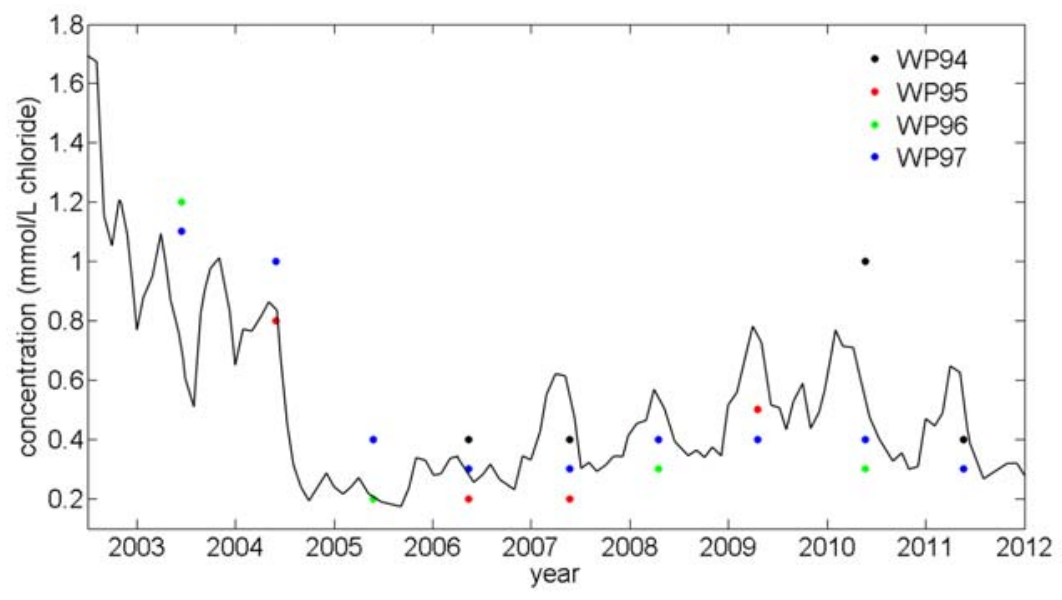

Figure ESM4 Comparison between calculated chloride concentrations in the extraction well (black line) and observed chloride concentrations in extraction wells 94 to 97 (symbols)
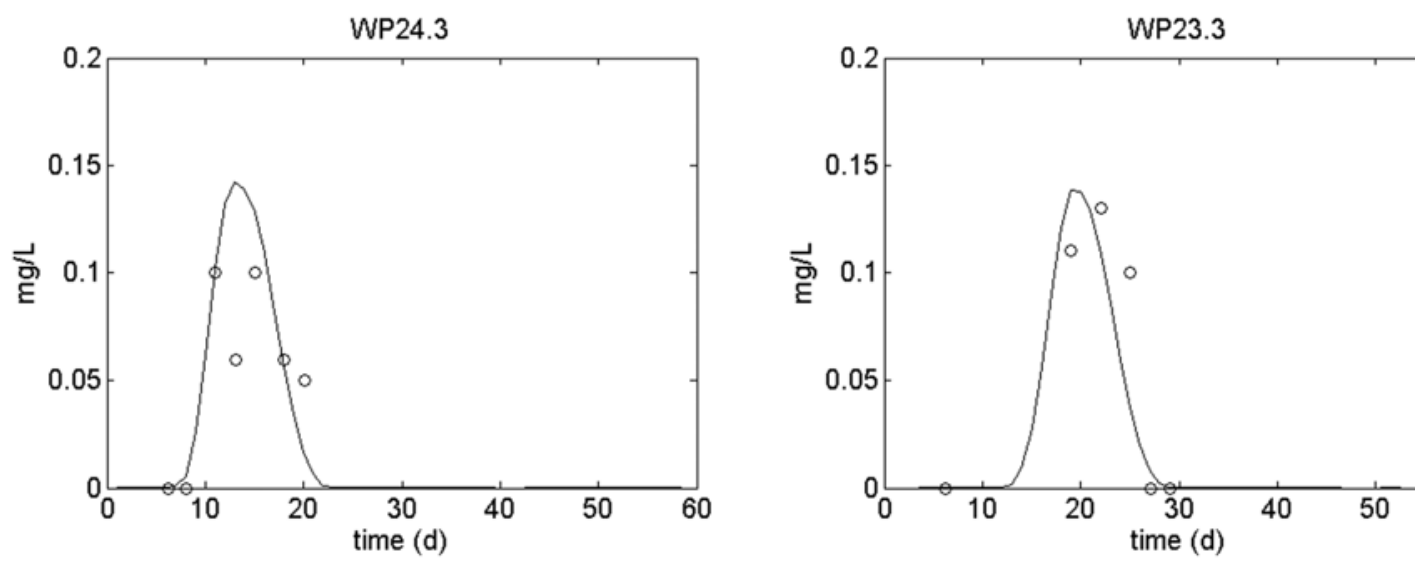

Figure ESM5 Comparison between calculated (black line) and observed (circles) breakthrough curves of fluoride during a tracer test 
A tracer test was performed in July 2006 (Vandenbohede et al., 2008). Therefore, NaF was dissolved in the infiltration water where fluoride was used as a conservative tracer. After addition of the tracer, fluoride concentration in the eastern pond measured $0.95 \mathrm{mg} / \mathrm{L}$. Breakthrough curves were recorded in WP24 and WP23. This tracer test was simulated by running the model with stress periods of 0.5 day during the two months (July and August) of the test. Fluoride was added as an extra species in the model. It was considered that fitting the time of maximum concentration (or tracer breakthrough) was the most important calibration objective since the method of fluoride analyses was less sensitive for small concentration (< $0.1 \mathrm{mg} / \mathrm{L}$ ). Therefore, uncertainty on these values is high. Considering this, Figure ESM5 indicates a reasonably good comparison between calculated and observed fluoride concentrations.

\section{References}

Vandenbohede A, Van Houtte E, Lebbe L (2008). Groundwater flow in the vicinity of two artificial recharge ponds in the Belgian coastal dunes. Hydrogeology Journal 16:1669-1681.

Vandenbohede A, Van Houtte E, Lebbe L (2009) Water quality changes in the dunes of the western Belgian coastal plain due to artificial recharge of tertiary treated wastewater. Applied Geochemistry 24:370-382. 